\title{
Erratum to: Cor triatriatum dexter: rare case of neonatal cyanosis
}

\author{
Katarzyna Januszewska • Markus Loeff • \\ Rainer Kozlik-Feldmann • Jörg Franke • \\ Heinrich Netz $\cdot$ Edward Malec $\cdot$ Robert Dalla Pozza
}

Published online: 1 October 2010

(C) Springer-Verlag 2010

\section{Erratum to: Clin Res Cardiol \\ DOI 10.1007/s00392-010-0212-0}

This article unfortunately contained errors. The legend belonging to Fig. 1 appeared with Fig. 2, and that of Fig. 2 was coupled with Fig. 1. Moreover, the legend of Fig. 3 contained superfluous text.

The three figures concerned are reproduced here with their correct legends.

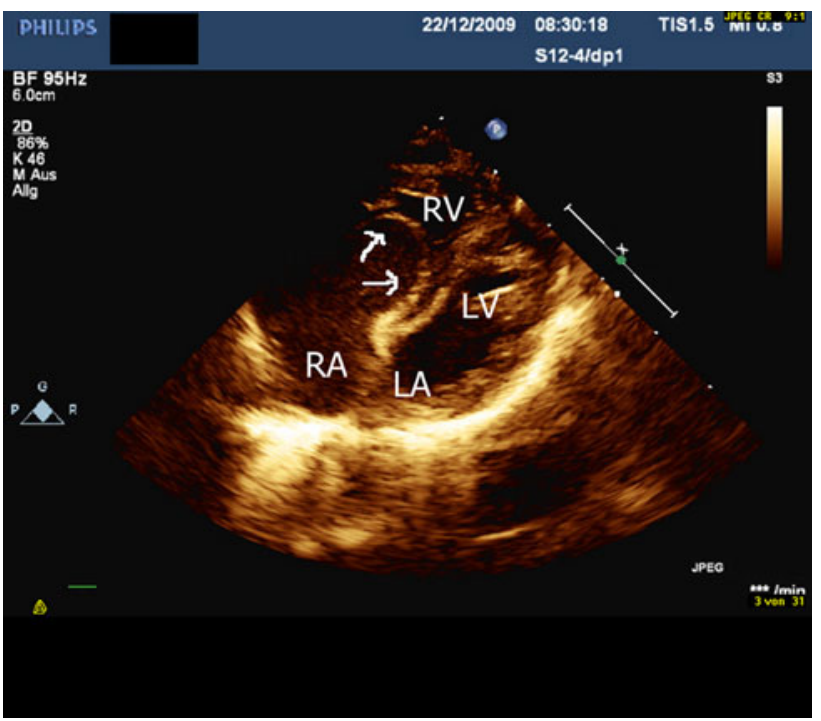

Fig. 1 Echocardiographic cross-sectional four-chamber-view with the membrane (arrows) bulging into the right ventricular inflow. $R A$ right atrium, $R V$ right ventricle, $L A$ left atrium, $L V$ left ventricle

The online version of the original article can be found under doi:10.1007/s00392-010-0212-0.

M. Loeff · R. Kozlik-Feldmann · H. Netz · R. Dalla Pozza ( $₫)$

Department of Pediatric Cardiology, Klinikum Großhadern,

Ludwig-Maximilians-University, Marchioninistr. 15,

81377 Munich, Germany

e-mail: Robert.DallaPozza@med.uni-muenchen.de

K. Januszewska $\cdot$ E. Malec

Department of Cardiac Surgery,

Ludwig-Maximilians-University, Munich, Germany

J. Franke

Children's Clinic, Kempten, Germany 


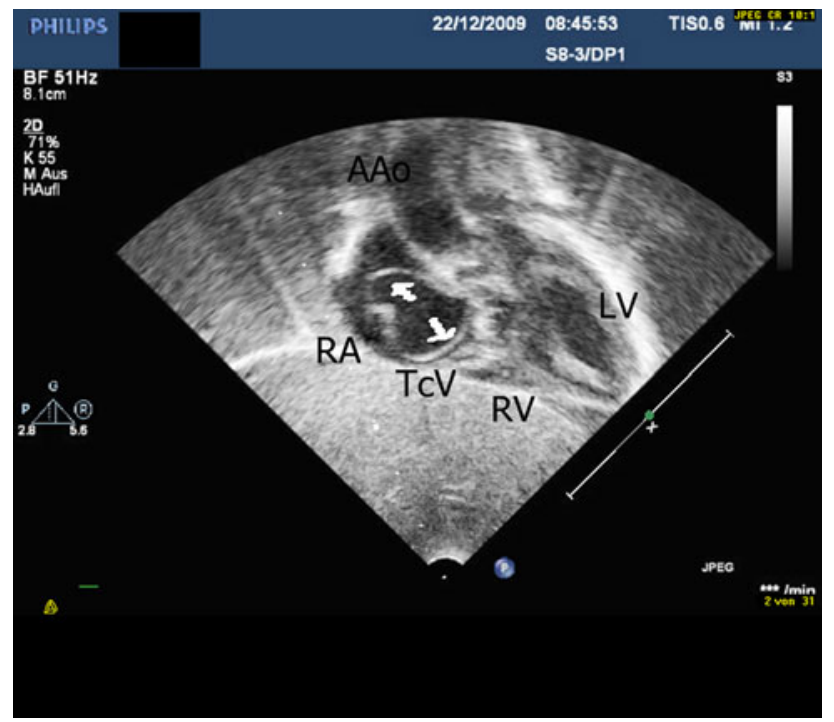

Fig. 2 Echocardiographic cross-sectional subcostal view with the right atrium $(R A)$ filled by a tiny membrane (arrows), obstructing the Tricuspid valve $(\mathrm{TcV})$ and bulging into the right ventricular inflow $(R V) ; A A o$ ascending aorta, $L V$ left ventricle

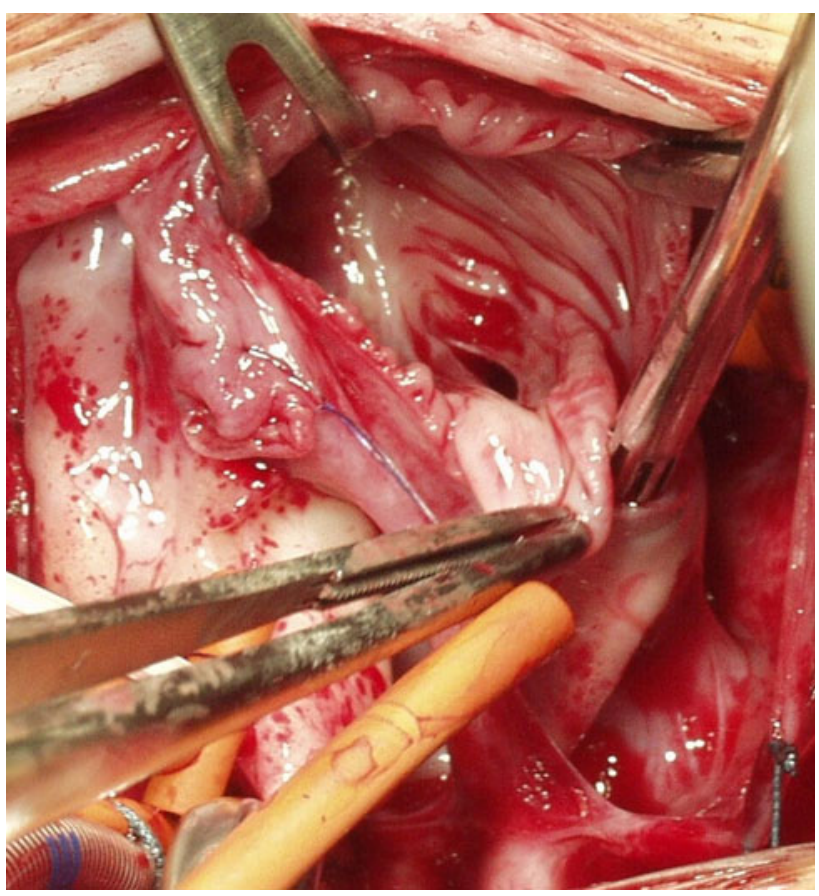

Fig. 3 Situs of the operation 